\title{
TRAMAS TEXTUALES DE LA MEMORIA COLECTIVA: LA «TRANSICIÓN A LA DEMOCRACIA» EN LOS MANUALES SECUNDARIOS DE HISTORIA ARGENTINA EN EL DESPUNTE DEL SIGLO XXI ${ }^{\alpha}$
}

\author{
Textual supports of collective memory: the "transition \\ to democracy" in Argentinean history high school text books \\ at the beginning of $21^{\text {st }}$ century
}

\section{Jorge Rolland ${ }^{\beta}$}

Fecha de recepción: 05/04/2019 • Fecha de aceptación: 11/06/2019

Resumen. El análisis de manuales escolares en torno a un tema inexplorado como la «transición a la democracia» muestra complejas relaciones entre el campo oficial, disciplinar y social. Se constata una secuencia común, con iconos y núcleos similares, y un marco compartido de significaciones (en torno al llamado «dualismo antinómico»), en una muestra de amplia circulación encuadrada en las reformas de 1993 y 2006. Ello remite a un producto aceptado y aceptable legal, económica, política, disciplinar y socialmente. Pero asimismo existen acentuadas divergencias historiográficas (sobre el cambio histórico y sus fundamentos, y la epistemología) y distintas relaciones con los relatos críticos (integral, institucional) y las memorias sociales (de los gobiernos constitucionales, de los organismos de derechos humanos y militar), a partir de los relatos de la ruptura, continuidad y transición propiamente. Esto indica, por su

\footnotetext{
${ }^{\alpha}$ Trabajo realizado en el marco de una beca posdoctoral financiada por el CONICET (Argentina), dirigida por Mario Carretero (Facultad Latinoamericana de Ciencias Sociales-Universidad Autónoma de Madrid) y vinculada al Proyecto PICT-2016-2341. Agradezco a mi director y a Gabriela Ossenbach, por acompañarme y ayudarme en estos otros momentos de transición que vivo; a Inesina, del Normal 2, y las bibliotecarias de La Plata, por su paciencia y ayuda cotidianas. En memoria de mi padre, José María Rolland, generoso traductor e infatigable luchador por los sentidos verdaderos del lenguaje.

B Instituto de Investigaciones Sociales de América Latina (FLACSO-CONICET), Ayacucho 555, C1026AAC, Ciudad Autónoma de Buenos Aires (Argentina). cronosytopoi@gmail.com (D) https://orcid.org/0000-0003-1637-1060
}

Cómo citar este artículo: Rolland, Jorge. «Tramas textuales de la memoria colectiva: la "transición a la democracia" en los manuales secundarios de historia argentina en el despunte del siglo xxI». Historia y Memoria de la Educación 11 (2020): 317-354 
parte, que los textos se entrelazan con las luchas de la historia y la memoria, con importantes implicaciones en la formación de los jóvenes.

Palabras clave: Memoria colectiva; Narrativas históricas; Representaciones sociales; Textos escolares; Transición a la democracia.

Abstract. The analysis of textbooks around an unexplored subject such as the "transition to democracy" reveals a complex interplay between the official, scientific and social realms. We find a common sequence of events, with icons and similar themes and with a shared conceptual framework of meanings (referring to the so-called "antinomic dualism»), in the context of a broad dissemination framed by the 1993 and 2006 reforms. This speaks of an accepted and acceptable pedagogical product from a legal, economic, political, scientific and social standpoint. But we also come across deep historiographical disputes (about historical change and its foundations, alongside epistemology) and varied interactions with critical accounts (comprehensive and institutional ones) and social memories (of constitutional governments, human rights organizations and the military), in relation to narratives about rupture, continuity and a transition per se. This reveals that texts intertwine with the struggles over history and memory, with relevant implications for youth training.

Keywords: Collective memory; Historical narratives; Social representations; Text books. Transition to democracy.

\section{INTRODUCCIÓN}

Los manuales escolares de la Argentina actual presentan nutridos contenidos sobre el pasado reciente, a raíz de la reforma educativa de 1993, con la Ley N² 4.195 Federal de Educación, y disposiciones legales subsiguientes, paradigmáticamente la Ley No 26.206 de Educación Nacional de 2006. Se ha subrayado el «rol estratégico» que desempeñan en la enseñanza de la Historia, ${ }^{1}$ aunque ya en la dictadura de 1976 a 1983, con la reforma del programa de Historia en 1979, fueron cruciales para la labor de adoctrinamiento. ${ }^{2}$ Sin embargo, desde los años ochenta, y particularmente desde mediados de los noventa, aumenta el espacio que se les dedica; según Nadia Zysman ocupan entre un 2,8 y un 3,3\% del

\footnotetext{
${ }^{1}$ Diego Ariel Born, «Las representaciones de la última dictadura militar. Los textos escolares de Historia en el nivel Secundario de la Ciudad de Buenos Aires, 1976-2009» (Tesis de Maestría, FLACSO, 2010), 28.

2 Born, «Las representaciones», 46-47.
} 
espacio total de los volúmenes, sobre todo en lo que toca al periodo de 1976-1983,3 y Diego Born estima que reciben el doble del espacio que se consagra al resto de años en la mayor parte de los manuales. ${ }^{4}$ Estos cambios son concomitantes con muchos otros que definen globalmente un punto de inflexión en la evolución de los textos escolares argentinos en estos momentos. ${ }^{5}$

En este trabajo nos proponemos discutir cómo está (y cómo no está) representado el pasado reciente en ellos, así como algunas implicaciones en relación con los esfuerzos que desde la escuela se realizan para que no se repitan los dolorosos procesos que forman parte de él. Para ello es fundamental considerar, en primer lugar, su especificidad como herramienta escolar que «recontextualiza» un saber disciplinar, experto, con fines pedagógicos, en el marco de políticas oficiales concretas; los textos no sólo trasladan a un formato pedagógico el conocimiento histórico y social, sino que producen nuevos sentidos en los que aquél adquiere formas particulares. ${ }^{6}$ Con ello, disputas clásicas historiográficas como las tensiones entre coyuntura y estructura, el papel de la agencia y la determinación estructural, la teleología y la multicausalidad, pueden estar presentes.

Pero, en segundo lugar, los manuales forman parte de la memoria colectiva y se vinculan específicamente con la dimensión pedagógica de la memoria; ${ }^{7}$ son parte de esas «otras instancias de transmisión» de la memoria, junto con la legislación. ${ }^{8}$ Por ello, también constatarán

\footnotetext{
${ }^{3}$ Nadya Zysman, De la «subversión marxista» al «terrorismo de Estado». Representaciones de la última dictadura militar en las narrativas históricas de la escuela media argentina (1983-2009) (Córdoba: Editorial Universitaria Villa María, 2015), 252.

${ }^{4}$ Born, «Las representaciones», 78 y 98.

5 Gonzalo De Amézola, «Capítulo VI. Cambiar la Historia. Manuales escolares, currículum y enseñanza de la historia reciente desde la transformación educativa», en Dictadura y educación. Volumen 3. Los textos escolares en la Historia argentina reciente, ed. Carolina Kaufmann (Buenos Aires: Miño y Dávila, 2006), 241-242.

${ }^{6}$ Basil Bernstein, Pedagogía, control simbólico e identidad (Madrid: Morata, 1998).

${ }^{7}$ Mario Carretero, Alberto Rosa y María Fernanda González, «Introducción. Enseñar historia en tiempos de memoria», en Enseñanza de la historia y memoria colectiva, comps. Mario Carretero, Alberto Rosa y María Fernanda González (Buenos Aires: Paidós, 2006), 18; Elisabeth Jelin, La lucha por el pasado. Cómo construimos la memoria social (Buenos Aires: Siglo XXI, 2017), 264-265.

8 Martín Legarralde, «Estudios sobre la transmisión escolar de las memorias de la última dictadura militar», Archivos de Ciencias de la Educación 6, no. 6 (2012). http://www.memoria.fahce.unlp.edu. ar/art_revistas/pr.5933/pr.5933.pdf.
} 
vínculos con contextos más amplios, incorporando las tensiones y luchas que les son propios, y además contribuirán a las representaciones sociales de estudiantes y docentes, con importantes implicaciones, ya que éstas suponen un «conocimiento práctico» con «un rol fuertemente orientador sobre los comportamientos». ${ }^{9}$

Como consecuencia de ambas cuestiones, nos preguntamos cómo se relacionan en los textos distintas esferas o contextos: el oficial (legal), el académico y el social. En un producto específicamente pedagógico, ¿cómo se presenta el discurso histórico? ¿Qué interpretaciones se ofrecen en términos historiográficos? ¿Qué vínculos pueden atestiguar con relación a las representaciones sociales de la historia? ¿Están presentes las memorias sociales, los sentidos del pasado que se hallan en otros contextos? ¿Qué implicaciones puede tener todo ello en la formación escolar de las nuevas generaciones?

\section{OBJETO Y ENFOQUE}

Los textos escolares entrañan una realidad multidimensional. La forma que proponemos aquí para abordarla es ceñirnos a la arquitectura conceptual que presenta una muestra particular; es decir, un análisis formal, de términos y expresiones que conforman campos semánticos concretos e interrelacionados, y que requieren determinadas interpretaciones, a través de un sinfín de elementos textuales y paratextuales, siguiendo el planteamiento de algunos trabajos de referencia en el campo específico de este estudio. ${ }^{10}$ Esta es la estrategia que, en mi opinión, mejor caracteriza las formas concretas en que toman cuerpo en los textos el discurso histórico y las disputas sobre el pasado, así como las conexiones con las memorias sociales y con las implicaciones que pueden tener estas elaboraciones en la formación de los jóvenes.

\footnotetext{
9 José Antonio Castorina, «Un encuentro de disciplinas: la historia de las mentalidades y la psicología de las representaciones sociales», en Enseñanza de la historia y memoria colectiva, comps. Mario Carretero, Alberto Rosa y María Fernanda González (Buenos Aires: Paidós, 2006), 77 y 83.

10 Fabiana Alonso, «La dictadura militar argentina (1976-1983) en los textos escolares de Ciencias Sociales e Historia para el Tercer Ciclo de la Educación General Básica», De Signos y Sentidos 2 (2004): 9-29; Fabiana Alonso, «Capítulo VII. La dictadura militar argentina (1976-1983) en los textos escolares de Ciencias Sociales e Historia para el tercer ciclo de la Educación General Básica», en Dictadura y educación. Volumen 3. Los textos escolares en la Historia argentina reciente, ed. Carolina Kaufmann (Buenos Aires: Miño y Dávila, 2006), 273-294.
} 
El estudio del pasado reciente en los textos escolares es muy limitado. Las tareas primordiales de la investigación en manuales se han dirigido a la conformación de inventarios y bases de datos, como representa paradigmáticamente el caso del Proyecto MANES, de la Universidad Nacional de Educación a Distancia (España), aunque desde los años noventa se ha reconocido su utilidad para analizar «el interior de la escuela» y la "cultura escolar». ${ }^{11}$ En el campo de la Historia y otras Ciencias sociales se ha privilegiado entender las relaciones con el nacionalismo. ${ }^{12}$ Con todo, en la actividad del pionero Georg Eckert Institut für internationale Schulbuchforschung (Brunswick, Alemania) fue crucial desde el principio el proceso de construcción (o refundación) nacional tras el nazismo y la Guerra precisamente en relación con la revisión del pasado reciente. ${ }^{13}$

En el caso particular de Argentina, el foco ha estado puesto en cómo se trata la dictadura de 1976-1983, en algunos estudios señeros realizados en los primeros 2000, como son los citados de Born, Zysman y Fabiana Alonso, a los que se añaden las compilaciones de Carolina Kaufmann ${ }^{14}$ y recientemente el repaso de Juan Acosta. ${ }^{15}$

Para el análisis propuesto aquí, se ha optado por un tema inexplorado hasta ahora: la llamada «transición a la democracia» (o sus equivalentes de «retorno» o «vuelta a» o «de la democracia»), es decir, el conjunto de procesos en torno a 1983, cuando se disuelve la última Junta

\footnotetext{
11 Gabriela Ossenbach, «Prólogo», en Dictadura y educación. Vol. 3, 7.

12 Graciela Carbone, Libros escolares. Una introducción a su análisis y evaluación (México: Fondo de Cultura Económica, 2003); Mario Carretero, Liliana Jacott y Asunción López-Manjón, «La enseñanza de la historia mediante los libros de texto: ¿se les enseña la misma historia a los alumnos mexicanos que a los españoles», en Aprender y pensar la historia, comps. Mario Carretero y James F. Voss (Buenos Aires y Madrid: Amorrortu, 2004), 153-172. Para el caso argentino ver Luis Alberto Romero (coord.), La Argentina en la escuela. La idea de nación en los textos escolares (Buenos Aires: Siglo XXI, 2004).
}

13 Kathrin Henne (ed.), Textbooks between tradition and innovation. A journey through the history of the Georg Eckert Institute (Brunswick: Georg Eckert Institute y Leibniz Institute for International Textbook Research, 2016).

${ }_{14}$ Carolina Kaufmann (ed.), Dictadura y educación. Volumen 3. Los textos escolares en la Historia argentina reciente (Buenos Aires: Miño y Dávila, 2006); Gonzalo De Amézola, Carlos Dicroce y María Cristina Garriga, "La última dictadura militar argentina en los manuales de Educación General Básica», en Textos escolares, dictaduras y después. Miradas desde Argentina, Alemania, Brasil, España e Italia, ed. Carolina Kaufmann (Buenos Aires: Prometeo, 2012), 103-134.

15 Juan Acosta, «La historia reciente en la escuela. Análisis de los manuales del nivel medio luego de la sanción de la Ley Nacional de Educación en 2006», Clio \& Asociados 20-21 (2015): 149-161. 
Militar, presidida por el General Reynaldo Bignone, y se proclama presidente electo al Doctor Raúl Alfonsín. Este recorte se justifica, en primer lugar, porque permite discutir el jugoso tema de las transiciones, en torno al cual se despliegan arduas polémicas historiográficas tanto en cuanto a la definición de las discontinuidades (o discordancias) como en lo que toca a las trayectorias de los grupos de poder y su reproducción. Y, en segundo lugar, reúne un conjunto de elementos para sustanciosos debates pedagógicos: las transiciones como momentos liminales en los que se abren y ocluyen determinadas opciones políticas, contextos de disputa y legitimación de múltiples agentes, origen (real o mítico) de las realidades contemporáneas... Llama la atención que un tema así no se investigue en el campo; incluso en el caso de una de las revistas del instituto Georg Eckert se ha tratado hace poco, pero más como periodo de producción de manuales que como objeto de estudio. ${ }^{16}$

Los trabajos citados sobre el pasado reciente en los manuales argentinos consideran que la realidad posterior a 1983 se presenta sustancialmente condicionada por los años previos y se encuadra en la oposición entre «democracia» y «autoritarismo», como parte de «un consenso básico» para «refundar una comunidad política basada en la institucionalidad democrática». ${ }^{17}$ Por otro lado, desde los 2000 se aprecia una tendencia a desdibujar esta oposición, a tenor de los vínculos instaurados en la dictadura de 1976 entre represión y política económica, con efectos a largo plazo, sobre todo en el "relato crítico integral», ${ }^{18}$ cosa que traza una "línea de continuidad» entre lo que sucede antes y después de 1983.19

En el presente trabajo, realizado sobre una muestra que en parte coincide con la de estos autores, veremos que es la realidad en torno a 1983 (o el contenido que se le atribuye) lo que condiciona la representación de lo anterior y que la oposición entre «democracia» y «autoritarismo» (o «dictadura») tiene una persistencia mucho mayor. Lo importante en el análisis no será aquí sólo constatar esta oposición, sino entender

\footnotetext{
${ }_{16}$ Kira Mahamud y Anna Ascenzi (eds.), «Textbooks in Periods of Political Transition after the Second World War. Special Issue», Journal of Educational Media, Memory and Society 9, no. 1 (2017): $1-117$.

17 Alonso, «La dictadura», 26; Alonso, «Capítulo VII», 281 y 288.

${ }_{18}$ Born, «Las representaciones...», 108-109.

19 Zysman, De la «subversión marxista», 251-252.
} 
sus términos y las relaciones que se establecen entre ellos. Por ello, nos proponemos analizar (i) cómo se conciben las realidades previas y posteriores a 1983, (ii) cómo se entienden específicamente las rupturas y las continuidades históricas entre ellas, (iii) cómo se caracteriza históricamente el proceso de transición y (iv) cómo se concibe la naturaleza y el proceso de elaboración del conocimiento histórico (o sea, los fundamentos epistemológicos). Como resultado apreciaremos la existencia de tres grandes relatos (el de la ruptura, la continuidad y la transición propiamente) que manifiestan un complejo panorama que será discutido para terminar y que entraña relaciones específicas entre los textos, la historiografía y la memoria colectiva.

\section{MUESTRA}

La selección de los volúmenes se ha realizado en función de la disponibilidad en bibliotecas y librerías, y de los datos sobre las tiradas. Como este estudio se enmarca en una investigación educativa en la ciudad de La Plata, capital de la Provincia de Buenos Aires, entre 2017 y 2018, las bibliotecas de referencia han sido la Biblioteca Central de la Provincia de Buenos Aires y la Biblioteca Central de la Universidad Nacional de La Plata, y las de las dos escuelas donde se ha realizado dicho trabajo: la Escuela Normal Superior $\mathrm{N}^{\circ} 2$ «Dardo Rocha» y el Colegio Corazón Eucarístico de Jesús. Las librerías, por su parte, incluyen las más conocidas de la ciudad: Rayuela y La Normal. En cuanto a los datos sobre las tiradas de ejemplares de las distintas editoriales, se han considerado los aportados por Born en el Apéndice II de su publicación; reflejan la amplia distribución que tienen los textos seleccionados aquí (figura 1). 
Figura 1. Distribución comercial de manuales en Argentina entre 2004 y 2009

\begin{tabular}{|c|c|c|c|}
\hline Editorial & Año de edición & $\begin{array}{l}\text { Tirada en } \\
\left(n^{\circ} \text { de }\right.\end{array}$ & $\begin{array}{l}\text { y } 2009 \\
\text { ires) }\end{array}$ \\
\hline \multirow{2}{*}{ Aique } & 1999 & 30.000 & \multirow{2}{*}{48.000} \\
\hline & 2007 & 18.000 & \\
\hline Estrada & 2000 & & 10.000 \\
\hline \multirow{2}{*}{ Kapelusz } & 2000 & 10.000 & \multirow{2}{*}{16.000} \\
\hline & 2005 & 6.000 & \\
\hline \multirow{3}{*}{ Maipue } & 1999 & 3.000 & \multirow{3}{*}{12.500} \\
\hline & 2003 & 7.000 & \\
\hline & 2006 & 2.500 & \\
\hline \multirow{3}{*}{ Santillana } & 2005 & 10.000 & \multirow{3}{*}{62.500} \\
\hline & 2007 & 11.000 & \\
\hline & 2008 & 41.500 & \\
\hline Tinta Fresca & 2006 & & 30.100 \\
\hline
\end{tabular}

En consecuencia, se ha trabajado con ediciones relativamente recientes de las editoriales Aique, ${ }^{20}$ Estrada, ${ }^{21}$ Kapelusz, ${ }^{22}$ Maipue, ${ }^{23}$ Santillana ${ }^{24}$ y Tinta Fresca. ${ }^{25}$ Todas ellas corresponden a la nueva era que definíamos al principio, de manera que sus características no representan

20 María Ernestina Alonso y Enrique C. Vázquez, Historia: la Argentina contemporánea: 1852-1999 (Buenos Aires: Aique, 2006 [2000]).

${ }_{21}$ Patricia Piccolini et al., Historia. El mundo contemporáneo (Buenos Aires: Estrada, 2008).

22 Cristina Rins y María Felisa Winter, La Argentina. Una historia para pensar 1776-1996 (Buenos Aires: Kapelusz, 1999); Gonzalo De Amézola et al., Historia argentina y latinoamericana II en el contexto de las transformaciones mundiales (desde 1930 hasta el presente) (Buenos Aires: Kapelusz/Norma, 2004). Para distinguir ambas ediciones nos referiremos a los años de edición correspondientes a cada volumen.

${ }_{23}$ Teresa Eggers-Brass, Historia VI: historia reciente en la Argentina (Ituzaingó: Maipue, 2016).

24 Andrea N. Andújar et al., Historia argentina en el contexto latinoamericano y mundial (1850 hasta nuestros días) (Buenos Aires: Santillana, 2012); Andrea N. Andújar et al., Historia. $5^{\circ}$ año (Buenos Aires: Santillana, 2017). Para distinguirlas aplicamos el mismo criterio que con los textos de Kapelusz.

25 Leandro Losada et al., Historia 2. Historia argentina y latinoamericana (1900-2005) (Buenos Aires: Tinta Fresca, 2007). 
cambios a lo largo del tiempo sino concepciones diversas en el marco de esa gran etapa, como incluso los trabajos diacrónicos han constatado. ${ }^{26}$ Al presentar un análisis formal, no se han tratado aspectos que pueden ser pertinentes en estudios más comprensivos, como los entresijos de las editoriales y equipos de redacción, como hace en parte Zysman.

La selección de páginas ha sido necesariamente artificial. Por un lado, al ser un tema bisagra, la «transición» aparece tanto en los capítulos o páginas dedicados a la dictadura de 1976-1983 como en los que se ocupan de la evolución histórica desde 1983; en el primer caso, el corte lo establecemos en las secciones más o menos explícitamente consagradas al tema (por ejemplo en el caso de la edición de 2004 de Kapelusz, «El fin de la dictadura y la vuelta a la democracia»), aunque se podría ampliar (en ese mismo volumen: «La crisis del régimen militar»), y en el segundo lo llevamos hasta 1989 (salvo en los pasajes en los que se aluda explícitamente a temas conectados con nuestro objeto en una fecha posterior), que es el cierre cronológico más recurrente. Por otro lado, aunque el concepto de transición normalmente se liga con la política, hay referencias a él, en algunos manuales en los que se combina el estudio diacrónico con el temático, como en la edición de 1999 de Kapelusz y en la de Tinta Fresca, también en aquellos que abordan los aspectos económicos, sociales y culturales, de manera que en ocasiones se han incluido también esos pasajes.

\section{ANÁLISIS}

En un primer nivel, relativo al espacio dedicado al pasado reciente (figura 2), apreciamos la existencia de dos grandes grupos: un conjunto que pasa muy de puntillas por los periodos de 1976 en adelante, como los textos de Estrada, Kapelusz (1999) y Tinta Fresca, y el resto, que manifiesta un tratamiento extenso y/o equilibrado respecto de otras etapas (Aique, Kapelusz 2004, Maipue y las dos ediciones de Santillana).

En verdad, todos revelan elevadas proporciones (del 10\% al 26\%), incluso mayores que las que citábamos más arriba del estudio de Zysman, aunque en el caso del periodo concreto en torno a 1983 (hasta 1989) son en general reducidas (cerca del $2 \%$ ). Las excepciones son, del

${ }^{26}$ Por ejemplo, Born, «Las representaciones», 118, 127-128. 
lado de los índices altos, Aique (26,3 y 6,3\% para el pasado reciente en general y nuestra etapa en particular) y, del lado de los bajos, Kapelusz (1999) (5 y 1\%, respectivamente); el caso de Maipue (68 y 20,5\%) se comprende porque está enteramente dedicado a la evolución de 1970 en adelante. ${ }^{27}$

Figura 2. Porcentaje de páginas dedicadas al pasado reciente (1976 en adelante) y particularmente al periodo 1983-1989

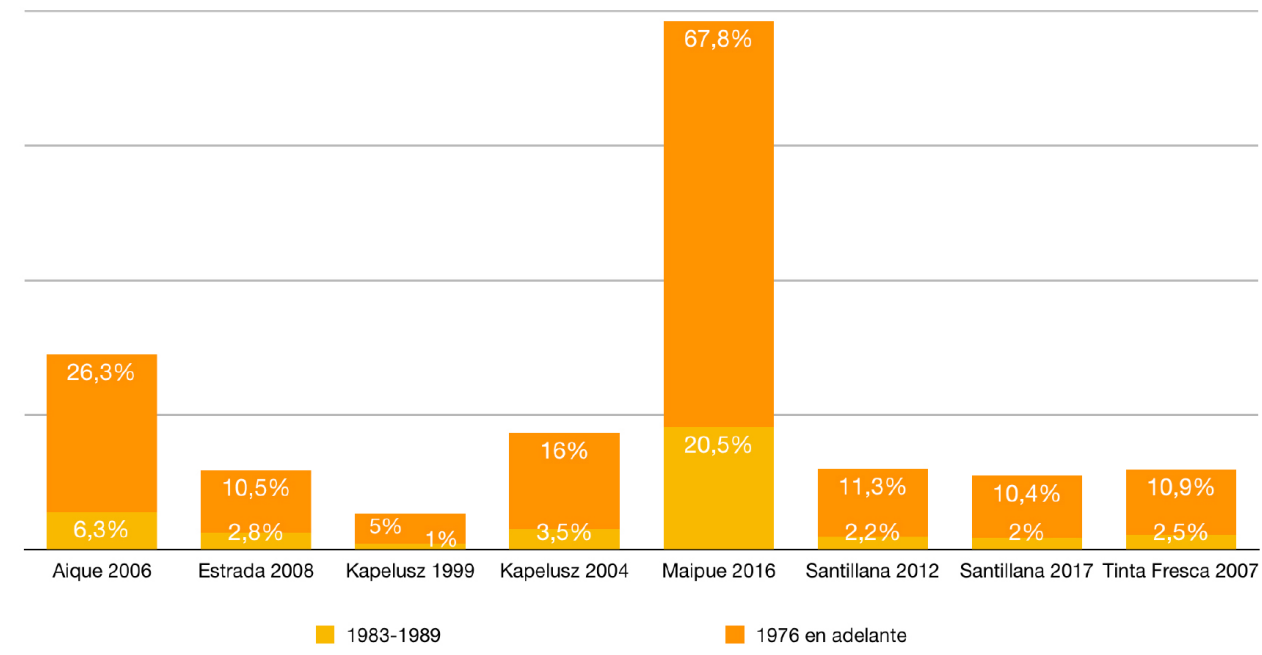

Sin embargo, hay que tener en cuenta el espacio dedicado a estos temas en relación con el que se dedica a otros en el conjunto de cada obra: no es igual el porcentaje (2\%) de páginas dedicadas al periodo 1983-1989 en una obra consagrada sólo a la segunda mitad del siglo XX, como la de Santillana (2017), y en otra que abarca todo el siglo XX, como la de Tinta Fresca, ni el que se obtiene de un volumen centrado exclusivamente en Argentina, como los de Kapelusz (1999) (1\%) y Aique $(6 \%)$, y el de un texto que abarca, además, el contexto internacional, como el de Santillana (2012) (2\%) y Kapelusz (2004) (4\%). Para caracterizar esa relación, Born propuso el cálculo de un índice que vamos a

\footnotetext{
${ }^{27}$ Aquí quedan excluidas del cálculo las páginas dedicadas a los capítulos de índole teórico-metodológica (pp. 11-82, capítulos 1 a 4).
} 
aplicar aquí28 y que vincula el número de páginas dedicadas a nuestros temas o periodos (1983-1989 y 1976-1983) y al conjunto de la historia argentina, y el número de años propios de esos periodos y del conjunto de cada obra (figura 3). ${ }^{29}$

Figura 3. Datos empleados para elaborar el índice sugerido por Born correspondiente al tema y periodo de 1983-1989. Se especifican, de paso, las páginas consultadas específicamente para este trabajo

\begin{tabular}{|c|c|c|c|c|c|c|c|c|}
\hline Manual & Aique 2006 & Estrada 2008 & Kapelusz 1999 & Kapelusz 2004 & Maipue 2006 & $\begin{array}{l}\text { Santillana } \\
2012\end{array}$ & $\begin{array}{l}\text { Santillana } \\
2017\end{array}$ & $\begin{array}{l}\text { Tinta Fresca } \\
2007\end{array}$ \\
\hline $\begin{array}{l}N^{\circ} \text { páginas dedicadas al tema } \\
\text { (páginas concretas) } / \mathrm{n}^{\circ} \text { años } \\
\text { periodo concernido }\end{array}$ & $\begin{array}{c}23(\mathrm{pp} . \\
305-9 \\
318-35) / 7\end{array}$ & $\begin{array}{c}6,5 \text { (pp. } 184-5 \\
188-9,192-3 \text { y } \\
194-5) / 7\end{array}$ & $\begin{array}{c}4(\text { pp. } 481-2, \\
532-3,536) / 7\end{array}$ & $\begin{array}{l}10 \text { (pp. 221, } \\
224-32) / 7\end{array}$ & $\begin{array}{l}23(\mathrm{pp} .122 \\
155-76) / 7\end{array}$ & $\begin{array}{c}8 \text { (pp. } 276 \\
280-1,320-5) \\
/ 7\end{array}$ & $\begin{array}{l}5 \text { (pp. 187, } \\
218-21) / 7\end{array}$ & $\begin{array}{l}8 \text { (pp. 165-6, } \\
198-203) / 7\end{array}$ \\
\hline $\begin{array}{l}N^{\circ} \text { páginas historia argentina - } \\
n^{\circ} \text { páginas periodo concernido }\end{array}$ & $359-23$ & $80-6,5$ & $539-4$ & $139-10$ & $112-23$ & $181-8$ & $54-5$ & $291-8$ \\
\hline $\begin{array}{l}\text { Total } n^{\circ} \text { años historia } \\
\text { argentina - años periodo } \\
\text { concernido }\end{array}$ & $148-7$ & $132-7$ & $187-7$ & $72-7$ & $30-7$ & $157-7$ & $52-7$ & $106-7$ \\
\hline
\end{tabular}

Vemos, con ello (figura 4), que en manuales como los de Kapelusz (1999), Estrada y Tinta Fresca los índices del periodo de 1983-1989 son muy bajos, pero, además, lo son igualmente los del periodo de 19761983 (en relación con el espacio que se dedica a otros); en el del último caso se halla incluso por debajo del índice de la «transición». En cambio, en el resto, el espacio dedicado a este tema es relativamente reducido también, pero el del periodo de 1976-1983 es bastante mayor; lo que marca la diferencia es la proporción de espacio dedicado al tema de la dictadura en relación con el que se dedica al periodo de 1983-1989 y otros.

\footnotetext{
${ }_{28}$ Born, «Las representaciones», nota 31.

${ }^{29}$ Las operaciones incluyen, por un lado, dividir la cantidad de páginas dedicadas al periodo que corresponda (1976-1983 ó 1983-1989) entre los años de cada periodo (8 y 7, respectivamente); por otro, restar el número de páginas de cada volumen sobre historia argentina y el número de páginas del periodo elegido; finalmente, restar el número de años del periodo temporal abarcado por el texto y el número correspondiente al periodo elegido (en la figura 3 recogemos los datos relativos a la etapa 1983-1989). Las cifras de estas dos últimas operaciones deben dividirse, y con la resultarse y la cifra de la primera debe hacerse lo propio.
} 
Figura 4. Índice del espacio dedicado a cada año de los periodos 1983-1989 y 1976-1983 en relación con el que se dedica a cada año del resto de periodos cubiertos por cada manual analizado

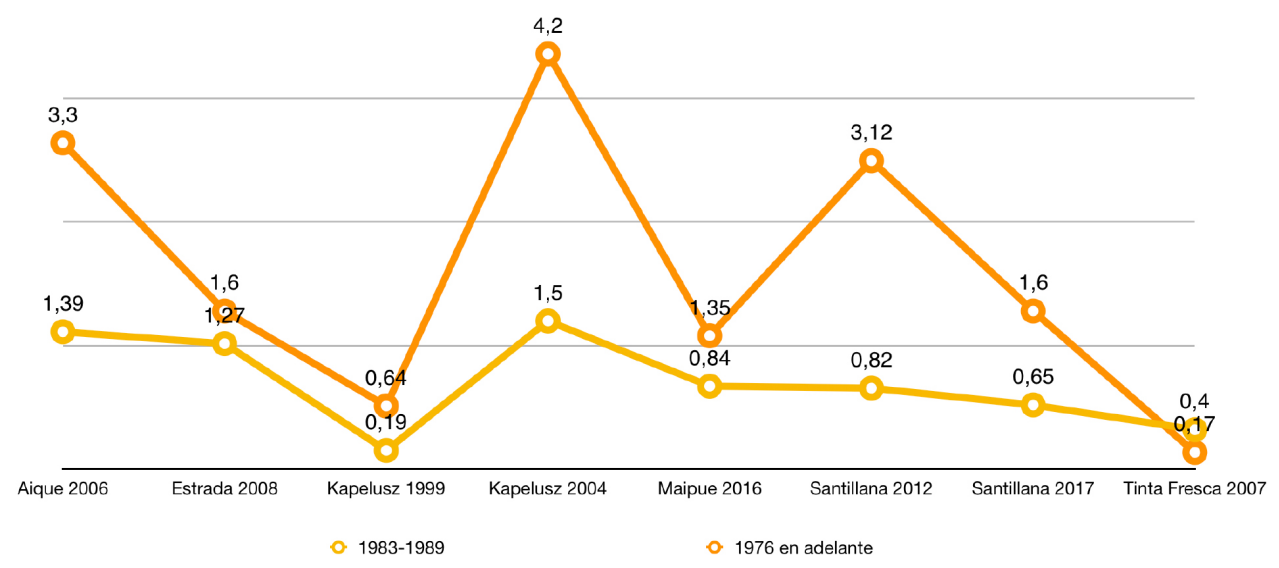

Ello lleva a matizar el tratamiento aparentemente similar de las ediciones de Estrada, Santillana (ambas ediciones) y Tinta Fresca, y las relativamente elevadas proporciones, sobre todo en el caso de Aique, Kapelusz (2004) y Maipue, que apreciábamos en la figura 2. Los índices de este último son bajos porque el conjunto del texto cubre un arco temporal muy restringido y el tratamiento de cada una de sus fases es muy equilibrado.

En un segundo nivel de análisis, de tipo cualitativo, apreciamos que esta oposición en dos grandes grupos se mantiene, aunque el segundo manifiesta una diversificación. Al hablar de historia, nos referimos a relatos, definidos de acuerdo con el tipo general de relaciones que establecen con respecto a las realidades previas y posteriores a 1983: de ruptura en un caso y de continuidad en otro. Huyendo de dicotomías, pero atendiendo también a la arquitectura conceptual, distinguimos este último de otro que, a pesar de que defiende ciertas continuidades entre unas y otras, lo hace en unos términos que llevan a singularizarlo como el de la transición propiamente. La tipología es artificial, obviamente, pero la gran variedad de características puede ser relacionada y deslindada en estos grupos de un modo coherente y estable. 
En este nivel, aun así, hay una serie de elementos comunes a todos los relatos. Primero, se consagra una periodización específica: una etapa de 1976 a 1983/1984 y otra de 1983/1984 en adelante (normalmente 1989), con una subetapa entre ambas que arranca en 1981 y derivaría de la «crisis»(de la dictadura). Segundo, esta subetapa presenta una secuencia canónica, que incluye la guerra de Malvinas, las elecciones presidenciales, el juicio a las Juntas, las «leyes de impunidad», las rebeliones «carapintadas» y el intento de toma de La Tablada. Y actúan como icónicos ciertos lugares (principalmente de la Ciudad de Buenos Aires, como la Plaza de Mayo) y personajes, tanto colectivos (Madres y Abuelas, partidos políticos, gobierno, militares...) como individuales (Raúl Alfonsín, Bignone, Ernesto Sábato, Aldo Rico...). Asimismo, el núcleo de la narración remite a los procesos judiciales en relación con (lo que se concibe como) la etapa previa.

Finalmente, hay dos matrices que dan sentido profundo a la «transición». Por un lado, va más allá de lo institucional y se liga con los «valores», cuando se reitera la fórmula de que «con la democracia se come, se educa, se cura $»^{30}$ o se emplea la expresión «cultura democrática».31 Por otro, aporta, con la Guerra de Malvinas, la clave fundamental para entender lo anterior, y no al revés; en ella se produce la verdad sobre el pasado y el presente. Así, las «cifras [de la Comisión Nacional sobre la Desaparición de Personas, en adelante CONADEP] demuestran que la represión clandestina implementada en estos años [...] [fue] parte de un plan sistemático dirigido desde el Estado", 32 y es en el capítulo dedicado a la dictadura de 1976-1983 en el que esta Comisión desempeña un papel narrativo destacado (a través de las portadas de su informe, el Nunca Más, y de sus conclusiones). ${ }^{33}$ En este contexto, la labor de los testimonios (y los archivos) será clave, pues «los jefes militares comenzaron por negar todo. [E]mpezaron a difundir la idea de que algunos hombres y bandas, descontrolados de sus mandos, estaban cometiendo errores y excesos [...]. Durante 1983 y 1984, los miles de testimonios reunidos permitieron a la

\footnotetext{
30 Eggers-Brass, Historia VI, 156; Santillana, Historia argentina (2012), 281.

31 Eggers-Brass, Historia VI, 156 (epígrafe de tercer nivel).

32 De Amézola et al., Historia argentina, 212.

33 De Amézola et al., Historia argentina, 208; Andújar et al., Historia argentina, 264; Alonso y Vázquez, Historia, 284-286 y fuentes 102, 103 y 105.
} 
CONADEP probar que no fue así»] $]^{34}$ Malvinas también habría revelado la «verdad» y acabado con los «engaños» respecto del momento. ${ }^{35}$ Como colofón, es esta verdad la que impulsa el propio proceso de cambio histórico en torno a 1983, pues son decisivos en su devenir el informe Rattenbach, el hallazgo de tumbas NN [sin nombre, del latín nomen nescio] y el testimonio de los ex combatientes. ${ }^{36}$

\section{El relato de la ruptura}

Los manuales que veíamos que dedican menos espacio al pasado reciente (figuras 2 y 4) constatan un relato que, en primer lugar, concibe la realidad en torno a 1983 como una bisagra entre dos cosas netamente diferenciadas y que entrañan una separación entre pasado y presente. Por un lado, este campo se despliega con motivo de la sucesión cronológica definida (más o menos explícitamente) por distintos epígrafes, como los de primer nivel de Tinta Fresca «la política entre 1955 y 1983» (Capítulo 6, p. 140) y «la Argentina contemporánea (1984-2005)» (Capítulo 8, p. 194) y el de segundo de Estrada «de la dictadura a la democracia» (Capítulo 9, p. 182). Por otro, se sostiene sobre una oposición ontológica, entre «dictadura» (o «autoritarismo») y «democracia»: en algunos casos se suprime la cronología de los epígrafes (en Kapelusz y Estrada), en otros se busca determinar «qué diferencia hay entre una dictadura y un gobierno democrático ${ }^{37} \mathrm{y}$, en general, se valora positivamente «la democracia» (frente a «la dictadura»), ya que no sólo se liga a vida (en la expresión «vida democrática»), sino que se asocia a «valor» (en su doble acepción de cualidad del ánimo y cualidad que hace a algo estimable). ${ }^{38}$ Y, finalmente, se considera «historia reciente» (o «muy reciente»), o se califica de «contemporánea», a la trayectoria posterior a 1983, rompiendo con lo anterior y privándolo de esas categorías. ${ }^{39}$

\footnotetext{
34 Alonso y Vázquez, Historia, 285.

35 Alonso y Vázquez, Historia, 298-300.

36 Alonso y Vázquez, Historia, 303 y 308; Rins y Winter, La Argentina, 481; Eggers-Brass, Historia VI, 148.

37 Piccolini, Historia, 183, actividad 2.

38 Piccolini, Historia, 182 y 185.

39 Rins y Winter, La Argentina, 531; Piccolini, Historia, 194.
} 
Esto no excluye cierta vinculación con la situación previa a 1976, a través de términos como «regreso», «vuelta», "restablecimiento», «restauración», "reinstauración», ${ }^{40}$ como tampoco algunas continuidades antes y después de 1983, especialmente en el plano económico, en cuanto a «las enormes deudas externas» y la «gravísima crisis económica».41 En Tinta Fresca se menciona el «nuevo paisaje social

En tercer lugar, la caracterización histórica tiende a naturalizar los acontecimientos y procesos, al asociar al campo específico de «el fin de la dictadura» términos como «derrumbe», «agotamiento», «ocaso», «colapso», "asfixia»,42 y emplear subordinadas adjetivas introducidas con participios: «acosado por [...], pero sobre todo acorralado por [...] Galtieri».43 La situación arrastra a los dictadores, ya que Bignone «debió convocar a elecciones nacionales»,44 acuciados por las circunstancias: «intempestivamente, se produjo [...] la Guerra de Malvinas»y «Galtieri cedió apresuradamente el gobierno». ${ }^{45}$ La sociedad argentina, presentada monolíticamente, es la que provoca el cambio, de un modo natural, fisiológico: «la actividad y la discusión [...] habían comenzado a renacer en la sociedad» ${ }^{46} \mathrm{y}$ "[l] os argentinos emergieron como de un sueño».47 Ante ello sólo queda el esoterismo: "exorcisar [sic] a los demonios».48 Además, se traza una relación externa o ajena, no histórica, entre determinados elementos, como «la economía» y «el gobierno», antes de 1983 ( «la economía no respondía a las medidas implementadas por el gobierno») ${ }^{49}$ y después («la crisis económica [fue] la otra grave dificultad que debió enfrentar el gobierno de Alfonsín»). ${ }^{50}$

\footnotetext{
40 Losada, Historia 2, 182 y 184; Rins y Winter, La Argentina, 529 y 533; Piccolini, Historia, 195 y 198.

${ }^{41}$ Losada, Historia 2, 185 y 198.

42 Piccolini, Historia, 165; Rins y Winter, La Argentina, 479.

43 Rins y Winter, La Argentina, 481.

${ }^{44}$ Losada, Historia 2, 189.

45 Piccolini, Historia, 165; Rins y Winter, La Argentina, 481.

46 Piccolini, Historia, 165.

47 Rins y Winter, La Argentina, 481.

${ }^{48}$ Rins y Winter, La Argentina, 532.

49 Rins y Winter, La Argentina, 479.

${ }^{50}$ Losada, Historia 2, 193.
} 
Complementariamente, predomina la teleología, pues «[e]l cambio era inevitable también en la Argentina» y las elecciones fueron la «única salida posible», mientras la guerra de Malvinas habría sido «un acontecimiento destinado a cambiar el curso político y la trayectoria vital de muchos argentinos». ${ }^{51} \mathrm{El}$ destino remite a la realización de una esencia previamente existente, «la unión nacional», especialmente al plantearse "la impostergable convivencia de los argentinos».52 Esta perspectiva se refuerza con abundantes artículos definidos: «la transición a la democracia», «la reinstauración del sistema democrático» o directamente «la democracia». 53

Y se combina con la racionalidad instrumental, como bien ilustra «el proceso de desmilitarización ${ }^{54}$ o ${ }^{5}$ despolitización ${ }^{55}$ de las Fuerzas Armadas en torno a 1983, que supone el encauzamiento de un cometido evidente por sí mismo y meramente utilitario. Así, aquéllas se limitaron $\mathrm{a}$ «concentrarse en sus asuntos profesionales» $\mathrm{y}$ «[a] renunciar a involucrar a la institución en aventuras políticas» para las que simplemente «no estaban preparados». ${ }^{56}$ Esas «aventuras» habrían sido una entre otras «opciones» (entendidas en un sentido meramente instrumental, esto es, para abocar a «soluciones»); en ese contexto, «la solución militar, que había sido una de las opciones por la que amplios sectores sociales y políticos habían apostado en el pasado frente a la inestabilidad o al caos político, desapareció como opción». ${ }^{57}$

Aun así, junto a todo ello se admite cierta indeterminación en el proceso, ya que se emplean verbos que entrañan acciones no completadas, artículos indefinidos, preposiciones de movimiento e incluso omisiones de artículos; además de «búsqueda» y «construcción», ${ }^{58}$ se habla de «una

\footnotetext{
51 Piccolini, Historia, 165; Rins y Winter, La Argentina, 482; Piccolini, Historia, 199.

52 Rins y Winter, La Argentina, 532 (texto de La República perdida) y 536 (foto de Marcelo Ranea «Las Madres de Plaza de Mayo y la policía»).

${ }_{53}$ Losada, Historia 2, 194; Piccolini, Historia, 198, 202; Rins y Winter, La Argentina, 481-482, 529 y 532.

${ }^{54}$ Losada, Historia 2, Cuaderno, 44-45.

55 Piccolini, Historia, 200-201.

56 Piccolini, Historia, 198; Losada, Historia 2, 185.

57 Piccolini, Historia, 198; Rins y Winter, La Argentina, 481-482.

${ }^{58}$ Rins y Winter, La Argentina, 532.
} 
trabajosa tarea hacia la reinstauración del sistema democrático»,59 así como de «una democracia posible». ${ }^{60}$ También debe matizarse que en algunos pasajes se menciona el papel opositor de los organismos de derechos humanos ${ }^{61}$ y se alude a las pugnas en el mismo seno de las Fuerzas Armadas. ${ }^{62}$ Por lo demás, la narración omite pugnas importantes como la planteada por la reivindicación de la comisión bicameral (en lugar de la CONADEP) y es refractaria al lenguaje más extendido en los últimos años entre los organismos de derechos humanos. ${ }^{63}$

Finalmente, la concepción epistemológica positivista de este relato separa netamente pasado y presente: la historia sería «el conjunto de acontecimientos ocurridos en el pasado, y el estudio de ese mismo pasado" ${ }^{64}$ por más que a veces se incluyan secciones como la de Relaciones, como en el caso de Estrada, ya que justo el capítulo del que nos ocupamos carece de ellas... De hecho, el estudio de «La Argentina contemporánea» es «inaccesible», sobre todo por la dificultad para ser «objetivo», ${ }^{65}$ y eso lleva en el manual de Kapelusz a cambiar «la metodología» de la exposición en «este periodo [que] está referido a una historia muy reciente». ${ }^{66}$ Todo ello redunda en la ruptura.

Además, el uso de comillas y del estilo indirecto da paso a veces a la supresión de las primeras y a la incorporación de la voz de referencia en el segundo, cosa que contradice la distancia que aparentemente pretenden y abunda en el espíritu esencialista y naturalizador mencionado. En el marco de nuestro tema, se habla de «el Proceso» ${ }^{67}$ y la «lucha contra la subversión», ${ }^{68}$ se señala que «la subversión fue erradicada» ${ }^{69} \mathrm{y}$

\footnotetext{
59 Piccolini, Historia, 198.

60 Rins y Winter, La Argentina, 528 y 532.

${ }^{61}$ Losada, Historia 2, 188; Piccolini, Historia, 200; Rins y Winter, La Argentina, 481.

62 Rins y Winter, La Argentina, 478-479 y 481.

${ }^{63}$ Losada, Historia 2, 188 para el término «memoria».

${ }^{64}$ Losada, Historia 2, 6-7.

65 Piccolini, Historia, 198.

66 Rins y Winter, La Argentina, 531 y Unidad 9 en general.

${ }^{67}$ Rins y Winter, La Argentina, 479; Piccolini, Historia, 282.

68 Losada, Historia 2, 184.

${ }^{69}$ Rins y Winter, La Argentina, 481 y 477.
} 
se emplean expresiones propias de los mandatos constitucionales para aludir a la sucesión de dictadores: «al terminar Videla su gobierno, asumió el general Roberto Viola» ${ }^{70}$ y más adelante se produjo la «asunción» de Galtieri y Bignone; ${ }^{71}$ también se señala que «[1]a Multipartidaria [fue una] organización que venía trabajando al margen de la autoridad oficial». ${ }^{72}$ A veces incluso se toma partido en una clara disputa por el pasado: «el golpe militar instaló lo que se denominó "terrorismo de Estado"».73

\section{El relato de la continuidad}

Entre los textos que dedican un espacio importante al pasado reciente (figuras 2 y 4) distinguimos un primer grupo integrado por las editoriales Aique y Maipue. Concibe las realidades en torno a 1983 como una bisagra entre dos etapas estrechamente relacionadas y subsumidas en un gran ciclo en el que, además, se incluye el presente. Así, el manual de Aique habla, en un epígrafe de primer nivel, de «Disciplinamiento y reorganización de la sociedad argentina (1976-1999)»,74 y el de Maipue remite directamente en su título a la "Historia reciente en la Argentina». Además, «dictadura» $\mathrm{y}$ «democracia» no se oponen, sino que se relacionan procesualmente: se articula un régimen («dictadura», "terrorismo de Estado») con un proceso («restablecimiento [...] y ajuste», «retorno»), ${ }^{75}$ y la propia morfología rompe la simetría de una tajante oposición: «la crisis de la dictadura militar» y «la experiencia sangrienta de la dictadura» (forma nominal), y «gobiernos democráticos» $\mathrm{y}$ «cultura democrática» (forma adjetival). ${ }^{76}$

Se plantea la existencia de una dialéctica entre continuidades y rupturas en torno a 1983, aunque son las primeras las privilegiadas, fundamentalmente por la transformación profunda y global a partir de 1976,

\footnotetext{
${ }^{70}$ Rins y Winter, La Argentina, 478.

${ }^{71}$ Piccolini, Historia, 163 y 165.

72 Rins y Winter, La Argentina, 481.

${ }^{73}$ Piccolini, Historia, 282.

74 Alonso y Vázquez, Historia, 266.

75 Alonso y Vázquez, Historia, 266 y 319; Eggers-Brass, Historia VI, 118 y 155.

${ }^{76}$ Eggers-Brass, Historia VI, 156; Alonso y Vázquez, Historia, 265, 294 y 318.
} 
al referirse al «Disciplinamiento y reorganización» y el «aniquilamiento [del otro] físico y psíquico» e "histórico y social»,77 cuya trascendencia rompe con lo previo y se proyecta en los años sucesivos. Se pueden rastrear esas continuidades antes y después de 1983, al vincular aspectos políticos y económicos en la fase previa («terrorismo de Estado» y «concentración económica») y posterior («restablecimiento de la democracia política» y «ajuste económico neoliberal»). ${ }^{78} \mathrm{Y}$ al mismo tiempo se señala explícitamente que «este retorno no significó la restauración del régimen político democrático con las mismas características que tenía antes de 1976», y es que "[1]as consecuencias que los casi ocho años de dictadura habían producido [...] se reflejaron en el plano de la política»;79 aun así, no es sólo cuestión de «consecuencias», porque «esos regímenes [autoritarios] existieron para implantar la desigualdad [...] que continuó con las políticas neoliberales». ${ }^{80} \mathrm{El}$ neoliberalismo, por cierto, epítome de esa radical transformación, articula y da continuidad a lo que viene antes y después de 1983: "Al modelo neoliberal pleno se llegó mediante el disciplinamiento de la sociedad en dos etapas: por un lado, el terrorismo de Estado [...] y por otro, el acorralamiento económico [...] [por] la hiperinflación». ${ }^{81}$

A esto se añaden multitud de elementos, como el uso habitual del presente de indicativo, la presencia de Videla y Viola en el nombramiento de la nueva dirección del Ejército en 1984, ${ }^{82}$ la vigencia del movimiento de derechos humanos, ${ }^{83}$ el despliegue de la ideología y los procedimientos de la dictadura en la represión de La Tablada, ${ }^{84}$ el poema de Víctor Heredia con que arranca el Capítulo 7 de Maipue y el desinterés hacia «el final de la dictadura» en este mismo texto, que no aparece en la «Breve cronología de los gobiernos de facto 1976-1983».

\footnotetext{
77 Alonso y Vázquez, Historia, 266; Eggers-Brass, Historia VI, 119.

78 Alonso y Vázquez, Historia, 266 y 318.

79 Alonso y Vázquez, Historia, 319-320, fuente 116.

${ }^{80}$ Eggers-Brass, Historia VI, 34.

81 Eggers-Brass, Historia VI, 177.

82 Alonso y Vázquez, Historia, 330.

${ }^{83}$ Alonso y Vázquez, Historia, 331.

${ }^{84}$ Eggers-Brass, Historia VI, 169-170.
} 
Con todo, también se alude a las rupturas antes y después de 1983, pero en un plano valorativo (volitivo) antes que descriptivo: aquéllas se presentan más como algo buscado que realizado. Por ejemplo, se habla de «"última dictadura" porque es última temporalmente y porque está en la voluntad de los argentinos que nunca más haya dictaduras». ${ }^{85} \mathrm{Y}$ se repiten los subjuntivos (con alguna apelación a «el pasado»): «[que] vuelvan al nido nuestros seres queridos», 86 "la construcción de un Estado de derecho donde se castigase a los máximos culpables ${ }^{87} \mathrm{y}$ «que fuera la Justicia y no sólo la Historia quien se encargara de revisar el pasado». ${ }^{88}$ En este sentido también pueden entenderse «los nuevos gobiernos democráticos», «un nuevo pacto político», un «nuevo orden constitucional». ${ }^{89}$ Finalmente, algunos procesos posteriores a 1989 manifiestan alguna ruptura (como culminación de la transición): la «subordinación definitiva del poder militar al constitucional» bajo Menem y Martín Balza ${ }^{90}$ y los «juicios por la verdad», la revocación de los indultos y la declaración de las leyes de Punto Final y Obediencia Debida como inconstitucionales, además de la «reanudación» de los juicios «durante la presidencia de Néstor Kirchner».91 También hay relaciones con las etapas previas a 1976: «restablecimiento», «retorno» y «recuperación»,92 y la «vuelta a casa» del citado poema de Heredia.

El proceso histórico de la «transición» se caracteriza en un sentido multicausal y, desde luego, más agencial y menos esencialista que el anterior. En este terreno, el antagonismo (la confrontación) desempeña un papel central; por eso se apunta que aconteció una «compleja lucha política» entre múltiples actores, ${ }^{93}$ y se repiten los términos proactivos de «voluntad», «querer», «decidir». .94

\footnotetext{
${ }^{85}$ Eggers-Brass, Historia VI, nota 3, 120.

${ }^{86}$ Eggers-Brass, Historia VI, 155 (citado poema de Heredia).

87 Eggers-Brass, Historia VI, 156.

88 Alonso y Vázquez, Historia, 305.

89 Alonso y Vázquez, Historia, 265, 302, 330 y 319.

90 Alonso y Vázquez, Historia, 334-335.

${ }_{91}$ Eggers-Brass, Historia VI, 170-171.

92 Alonso y Vázquez, Historia, 318 y 331-332; Eggers-Brass, Historia VI, 155 y 156.

${ }_{93}$ Alonso y Vázquez, Historia, 330.

${ }^{94}$ Alonso y Vázquez, Historia, 320; Eggers-Brass, Historia VI, 120.
} 
Este campo se puebla por palabras como «liberalización», «diálogo», "pacto», «concertación», «traspaso» y «salida democrática».95 Y es que hay una estrategia de «apertura política» con Viola y negociaciones entre militares y partidos políticos; ${ }^{96}$ de hecho, Bignone "preparó» esa «salida». ${ }^{97} \mathrm{La}$ «derrota» en Malvinas es aquí una muestra, o un factor, de esa «crisis»: «aceleró la crisis política del régimen militar». ${ }^{98}$ Es cierto que el proceso remite en definitiva a «la crisis económica y política» de la dictadura ${ }^{99} \mathrm{y}$ que hay términos naturalizadores, como «agotamiento» $\mathrm{y}$ «disolución», ${ }^{100}$ y se utilizan perífrasis modales de obligación, como «[Bignone] se vio obligado a establecer un cronograma electoral». ${ }^{101}$ Pero es un proceso histórico concreto el que obliga y conduce al agotamiento y disolución, y lo que se agota específicamente es «el tiempo político» y no otros aspectos. Marcadores de la agencia son también los movimientos de oposición ${ }^{102}$ y el propio Alfonsín, no sólo como paladín de la defensa del Estado de derecho sino también como manipulador (cuando se habla de «la estrategia de Alfonsín» y de sus declaraciones y actuaciones en torno al «pacto militar-sindical», el nombramiento de la Corte Suprema de Justicia, la sentencia del Juicio a las Juntas, la sublevación de Semana Santa de 1987 y La Tablada en 1989). ${ }^{103}$

En este relato a menudo los acontecimientos desbordan lo pautado; por ejemplo, «el juicio [a las tres primeras juntas] fue mucho más allá de lo que esperaba Raúl Alfonsín en su decreto».104 Y abundan los artículos indeterminados, como al hablar de «la construcción de un Estado de derecho [...] [para que] se encontrara un equilibrio en la sociedad». ${ }^{105}$

\footnotetext{
95 Alonso y Vázquez, Historia, 279, 301, 302 y 308; Eggers-Brass, Historia VI, 122.

96 Alonso y Vázquez, Historia, 294, 296 y 301.

97 Eggers-Brass, Historia VI, 122.

98 Alonso y Vázquez, Historia, 299.

99 Alonso y Vázquez, Historia, 294 (epígrafe de tercer nivel).

100 Alonso y Vázquez, Historia, 294; Eggers-Brass, Historia VI, 122.

101 Alonso y Vázquez, Historia, 305.

102 Alonso y Vázquez, Historia, 302-303.

103 Alonso y Vázquez, Historia, 309, 331 y 333; Eggers-Brass, Historia VI, 167 (texto y foto), 169-170.

104 Eggers-Brass, Historia VI, 164.

105 Eggers-Brass, Historia VI, 155 y 156.
} 
Además, las relaciones entre las Fuerzas Armadas y el poder civil se tratan aquí en términos de "subordinación [...] al nuevo orden constitucional» y "control civil sobre los militares». ${ }^{106}$ Finalmente, se abordan las polémicas sobre la jurisdicción en el procesamiento a las Juntas, la comisión bicameral y las tensiones por los indultos de Menem. ${ }^{107}$

Con todo, algunos artículos definidos otorgan un carácter predeterminado al proceso, cuando se alude a «la Argentina de la transición a la democracia»108 y a "las elecciones» de 1983; sin hablar de ellas previamente, se afirma que «[e]l 30 de octubre de 1983 se celebraron las elecciones». ${ }^{109}$ En Maipue se dan por sentados «el retorno», «la legislación», «la teoría [de los dos demonios]», «los indultos», «los juicios», «la Verdad». Asimismo, «la sociedad» o «la sociedad civil» es, como en el relato anterior, un conjunto homogéneo que vive una "toma de conciencia»,110 incluso se «conmociona»111 y determina el uso de categorías, como veíamos a propósito de "última dictadura». ${ }^{112}$ Finalmente, también aparece la relación externa o ajena entre elementos como «los gobiernos democráticos» y «la dictadura militar»: la «consolidación [democrática] no puede evitar los efectos políticos disciplinadores de las políticas neoliberales $[\ldots]$ iniciadas por la última dictadura militar». ${ }^{113}$

Este relato defiende un planteamiento positivista crítico que apuntala en varios sentidos la caracterización previa. Toda investigación histórica selecciona entre las distintas propuestas, y lo hace de acuerdo con el presente y el proyecto social de futuro que defendamos, con «nuestras preocupaciones del presente», ${ }^{114}$ en este caso con la "demanda social», el «imperativo social de la memoria».115 Nada de esto implica que se

\footnotetext{
106 Alonso y Vázquez, Historia, 300.

107 Alonso y Vázquez, Historia, 330 y 334-335; Eggers-Brass, Historia VI, 159-160.

108 Alonso y Vázquez, Historia, 331.

109 Eggers-Brass, Historia VI, 122.

110 Alonso y Vázquez, Historia, 303.

111 Eggers-Brass, Historia VI, 148.

112 Eggers-Brass, Historia VI, n. 3, 120; también 169 con motivo de «leyes de impunidad».

113 Alonso y Vázquez, Historia, 265.

114 Alonso y Vázquez, Historia, 318.

115 Eggers-Brass, Historia VI, 21 y 30.
} 
renuncie a un tratamiento «abierto» $\mathrm{y}$ «desapasionado» para cumplir con «la tarea de investigar buscando la verdad de lo acontecido»,116 pero sí lleva a "un relato histórico diferente». ${ }^{117}$ Es diferente porque se confronta con otros en el marco de un contexto manifiesto de «disputa por el pasado». ${ }^{118}$ Y lo es porque se construye no sólo conforme a esa demanda social, sino con respecto a un pasado «reciente», «un pasado que no pasa», en tanto sigue doliendo («una herida abierta», «una realidad negada por años») y se proyecta sobre el presente a través de «lo que estamos viviendo», de «las múltiples consecuencias que [...] todavía no terminaron de desencadenarse». ${ }^{119}$

Este es el correlato epistemológico de la continuidad (si no su fundamento) y va a entrañar actividades para discutir los «antecedentes»y las «diferencias» entre la dictadura de 1976-1983 y los periodos previos, así como las continuidades y rupturas en cuanto al declarado objetivo de "cerrar las heridas del pasado». ${ }^{120}$ También se confrontan los prólogos del Nunca Más de 1984 y de 2006 y se contextualiza el informe (como consecuencia de la decisión de «retratar a las víctimas sin su ideología política»).121 Asimismo se rechaza activamente la naturalización de las categorías empleadas, pues se discuten términos como «democracia», «Proceso de Reorganización Nacional», «última dictadura» $\mathrm{y}$ «genocidio», ${ }^{122}$ y se excluye sistemáticamente la forma «asumir» para dar cuenta de la sucesión de dictadores. ${ }^{123}$ Aun así, se incorporan algunos enunciados y giros de numerosos organismos de derechos humanos y científicos sociales ligados, de un modo u otro, a ellos: la «memoria» y el «recuerdo permanente» como «barrera contra la repetición», ${ }^{124}$ se suscribe el «objetivo de que Nunca Más [sic] existan regímenes

\footnotetext{
116 Eggers-Brass, Historia VI, 20.

117 Alonso y Vázquez, Historia, 318.

118 Eggers-Brass, Historia VI, 15.

119 Eggers-Brass, Historia VI, 11 y 12.

120 Alonso y Vázquez, Historia, 335 y 285.

121 Eggers-Brass, Historia VI, 159 y 162-163.

122 Eggers-Brass, Historia VI, 156, 119-120 y n. 3.

123 Alonso y Vázquez, Historia, 305 y 330; Eggers-Brass, Historia VI, 120-121.

124 Alonso y Vázquez, Historia, 265 (texto de Jelin).
} 
autoritarios y genocidas», 125 se reflejan (sin comillas) las consignas de numerosos organismos, ${ }^{126}$ se emplean como explicaciones del desarrollo del Juicio a las Juntas y los indultos de Menem y su posterior revocación, los argumentos de éstos, ${ }^{127}$ y se mantiene la rúbrica de «los derechos humanos» cuando se alude a las «terribles violaciones de los derechos humanos» ${ }^{128}$ y se ilustra la portada de Maipue con un cuadro de Carlos Gorriarena.

\section{La transición propiamente}

La edición de 2004 de Kapelusz y las de 2012 y 2017 de Santillana presentan nutridos contenidos sobre el pasado reciente (figuras 2 y 4), pero se mantienen a medio camino entre el de la continuidad y la ruptura. Se conciben los procesos en torno a 1983 como un momento de articulación entre dos realidades distintas, cuando no opuestas, que además están desligadas de la actualidad. Hay una sucesión de etapas diferentes: «La dictadura militar (1976-1983)» viene seguida de «El retorno de la democracia (1983-1989)»129 y abunda el epígrafe de «El fin de la dictadura y la vuelta a la democracia». ${ }^{130}$ Pero apreciamos también una oposición ontológica, dado el núcleo de los epígrafes de primer nivel, sobre todo en la primera edición de Santillana: «democracias y dictaduras» y «la democracia» (secciones 4 y 5), y dada también la falta de una cronología explícita en los de ambas; se produce un «reemplazo [de las dictaduras] por regímenes democráticos».131 Esto se reitera en la contraposición entre un «ellos» (dictadura-patria financiera-minorías totalitarias-pasado) y un «nosotros» (democracia-presente/futuro) en un discurso de Alfonsín, ${ }^{132}$ y en la asociación de términos positivos a «democracia» (por ejemplo «nuevas soluciones») y negativos a «dictadura» («fragmentación»,

\footnotetext{
${ }^{125}$ Eggers-Brass, Historia VI, 34.

126 Alonso y Vázquez, Historia, 307.

127 Eggers-Brass, Historia VI, 164, 166 y170-171.

128 Alonso y Vázquez, Historia, 265.

129 De Amézola et al., Historia argentina, módulos 11 y 12 (epígrafes de segundo nivel).

130 De Amézola et al., Historia argentina, 221; Andújar et al., Historia argentina, 276; Andújar et al., Historia, 187 (epígrafes de tercer nivel).

131 Andújar et al., Historia, 208.

132 Andújar et al., Historia, 218.
} 
«endeudamiento», «problemas»).133 Finalmente, el manual de Kapelusz incluye el antes y después de 1983 bajo un mismo epígrafe de primer nivel: «La crisis del petróleo, el ordenamiento mundial y los problemas de América Latina» (Parte III), pero éste no llega hasta la actualidad ( «19731990») y los procesos del después quedan así desligados del presente.

Con todo, este relato en ocasiones importantes desdibuja esta oposición (temporal y ontológica), ya que, como veremos, los polos se conectan a través del concepto de «legados» (en el caso de Santillana) o se subsumen bajo un mismo epígrafe (en el caso de Kapelusz). Igualmente, se recalca el proceso («fin», «vuelta», «retorno», «consolidación») por encima de la sustancia («dictadura», "democracia»), y aparecen, aunque no siempre, expresiones del tipo «vuelta/retorno a»; se defiende explícitamente la idea de José Nun de la transición a la democracia como «un proceso». ${ }^{134}$

En este relato, como en el de la continuidad, la «transición» es un momento definitorio de una dialéctica entre continuidades y rupturas, pero con un concepto central, el de «legados» (o «consecuencias» $\mathrm{y}$ «secuelas»), que la cualifica de un modo especial: las realidades en torno a 1983 son ajenas unas respecto a otras y no se relacionan históricamente; la continuidad de algunos aspectos de "la dictadura» se contempla como una presencia extraña a «la democracia», cosa que se aprecia en la oposición continua de estos términos en los enunciados: «las secuelas de la última dictadura militar fueron muy profundas. [Surgieron] problemas para los cuales la democracia tendría que encontrar nuevas soluciones». ${ }^{135}$ El núcleo de esta peculiar continuidad es, como en el relato anterior, la gran transformación del país a todos los niveles, a través de conceptos como «disciplinamiento», «refundación», "plan sistemático», «reestructuración de la sociedad» $\mathrm{y}$ «neoliberalismo», 136 pero, en lo que toca a este último, su continuación es meramente residual, como un «legado»;137 también se

\footnotetext{
133 Andújar et al., Historia, 208.

134 De Amézola et al., Historia argentina, 236-237.

135 Andújar et al., Historia, 187.

136 De Amézola et al., Historia argentina, 209, 212 y 216-217; Andújar et al., Historia argentina, 264; Andújar et al., Historia, 178, 182 y actividad nº 12 de 189.

137 Andújar et al., Historia, Sección 4 frente a 5.
} 
hablará de los «efectos» de este radical cambio en la sociedad de 1976 en adelante. ${ }^{138}$

Como consecuencia, quedan sin discutirse profundamente las «visibles continuidades»139 (apuntadas con habituales presentes de indicativo): las «heridas que aún siguen abiertas», las "grandes claudicaciones para la democracia», la lucha de los organismos de derechos humanos, que «continúa en nuestros días», la polémica en torno a las cifras de las víctimas de la represión y el que «los militares y los sectores sociales que los habían apoyado habían abandonado el gobierno, pero no necesariamente el poder». ${ }^{140}$

Las rupturas tienen en este relato un papel destacado, tanto en el nivel valorativo como en el descriptivo de la narración, combinando las ideas de fin o cierre y comienzo o apertura. Por ejemplo, en el acto del 10 de diciembre de 1983 comparecen gentes de diversas tendencias con «el deseo de festejar el retorno a la democracia y el final de la dictadura»;141 era una «nueva oportunidad». ${ }^{142} \mathrm{Y}$ es que ese momento representa "[e]l comienzo de una nueva etapa», "[u]n ciclo que se abre». ${ }^{143}$ La ruptura se sostiene sobre «las diferencias con el autoritarismo que se dejaba atrás», 144 al mismo tiempo que con la vinculación con las etapas previas a 1976; de ahí las repetidas alusiones a la «vuelta», «retorno», «regreso», «restablecimiento» y «recuperación». ${ }^{145} \mathrm{Y}$ también con respecto a otras «transiciones», como la española, gracias al Juicio a las Juntas, «un hecho $[\ldots]$ sin precedentes en el mundo».146

\footnotetext{
138 De Amézola et al., Historia argentina, 213.

139 Andújar et al., Historia argentina, 308.

140 Andújar et al., Historia, 178 y 179; De Amézola et al., Historia argentina, 232 y 221; Andújar et al., Historia argentina, 320.

141 Andújar et al., Historia argentina, 320; Andújar et al., Historia, 218.

142 De Amézola et al., Historia argentina, 164.

143 Andújar et al., Historia argentina, 320; Andújar et al., Historia, 218 (epígrafe tercer nivel).

144 Andújar et al., Historia argentina, 325.

145 De Amézola et al., Historia argentina, 221, 224 y 225; Andújar et al., Historia argentina, 280, 320 y 325.

146 Andújar et al., Historia, 219.
} 
La narración, mucho más sintética que la del relato de la continuidad, especialmente en Santillana, incluye aun así numerosos factores y por tanto se presenta más rica que la de la ruptura. Si bien se enmarca en «una profunda crisis en el régimen militar» o "crisis del Proceso», 147 la «oposición de las organizaciones de derechos humanos» (o «la presión social»), así como los desacuerdos en torno a «la convergencia», son fundamentales para echar atrás el plan de «los militares». ${ }^{148}$ Asimismo, se aborda la polémica sobre la jurisdicción del procesamiento a las Juntas y la comisión bicameral, ${ }^{149}$ y con motivo de la sentencia del Juicio se manifiesta aquí también la divergencia de posturas (con claras continuidades en los años sucesivos, por cierto). ${ }^{150}$ Sin embargo, personajes como Alfonsín son reducidos al papel de víctima entre ciertos sectores de las Fuerzas Armadas y «la gente», «la calle», «las plazas». ${ }^{151}$

Hay en este relato una presencia contradictoria de elementos teleológicos. Por un lado, el proceso sería necesario, al hablar de «una futura transición hacia la democracia», de lo «inminente» que era tras la guerra de Malvinas, de «las futuras elecciones» y de que "[l]as elecciones finalmente se realizaron». ${ }^{152}$ A ello contribuyen igualmente el número asignado a los polos de la pareja binaria: «dictaduras» frente a «la democracia», ciertas preposiciones (de contenido y no de dirección), como «[e]l regreso de la democracia», y los determinantes de lejanía («aquellas dictaduras») frente a los definidos («la democracia»); ${ }^{153}$ la vinculación entre «democracia» $\mathrm{y}$ "vida» también abunda en la pretendida necesidad de «la democracia». ${ }^{154}$ No obstante, se alude, por otro lado, a "un periodo democrático» y, como vimos, se emplea un enfoque procesual, que entraña asimismo un carácter abierto, dado el «rol activo que

\footnotetext{
147 De Amézola et al., Historia argentina 220-221; Andújar et al., Historia argentina, 271.

148 De Amézola et al., Historia argentina, 220-221; Andújar et al., Historia argentina, 271 y 276; Andújar et al., Historia, 185-186 y 219.

149 De Amézola et al., Historia argentina, 229; Andújar et al., Historia, 219.

150 De Amézola et al., Historia argentina, 230.

151 Andújar et al., Historia, 221.

152 Andújar et al., Historia argentina, 271; Andújar et al., Historia, 187.

153 Andújar et al., Historia argentina, 204 y 280 (epígrafe de primer nivel).

154 De Amézola et al., Historia argentina, 221.
} 
tiene la sociedad en la definición de los valores democráticos».155 Aquí, de nuevo, el proceso fue incierto: «Según lo establecido por los militares [...]. No obstante, los intentos resultaron vanos [...]. [Se produjo] la negativa de los partidos políticos».156

Por lo demás, la sociedad es un todo homogéneo y se acentúa la racionalidad instrumental, de modo similar al relato de la ruptura: "la sociedad buscaba dejar atrás un pasado cargado de violencia e intolerancia y apostaba por la vida en democracia». ${ }^{157}$ En consecuencia, esta sociedad figura como un ente pasivo, dependiente de la política del régimen: con Viola se iniciaría «un momento de distensión política y cultural que permitió que la sociedad comenzara a movilizarse».158 Por otra parte, la «crisis del Proceso» remite a «problemas»y «fracasos» (cuyas causas o motivaciones internas son relegadas): «cuando la nueva política económica de los Estados Unidos hizo que el crédito se encareciera [...], comenzaron los síntomas de un grave problema» y Malvinas representa «un estrepitoso fracaso»;159 la política posterior a 1983 se contempla nuevamente guiada por la búsqueda de «soluciones», como hemos visto, no siempre «logradas», ya que «[el gobierno] no logró introducir reformas estructurales». ${ }^{160}$ También hay una relación externa entre «El gobierno» $\mathrm{y}$ «los grupos de poder», pues aquél los «subestimó». ${ }^{161} \mathrm{Al}$ menos «la cuestión militar» se dirime en función de la «subordinación» como «necesidad política del gobierno» y de la dilucidación de responsabilidades de las Fuerzas Armadas en la represión de los años previos. ${ }^{162}$

Los fundamentos epistemológicos son menos explícitos que en otros casos, pero pueden vincularse con el positivismo crítico del relato de la continuidad. A pesar de que en el nivel descriptivo se desvincula pasado y presente, se asume una cierta relación entre uno y otro, como veíamos

\footnotetext{
155 Andújar et al., Historia, 187 y 188.

156 Andújar et al., Historia argentina, 276.

157 De Amézola et al., Historia argentina, 221.

158 Andújar et al., Historia argentina, 271.

159 Andújar et al., Historia argentina, 271 y 272.

160 De Amézola et al., Historia argentina, 225.

161 Andújar et al., Historia argentina, 320; De Amézola et al., Historia argentina, 227.

162 De Amézola et al., Historia argentina, 229; Andújar et al., Historia, 219.
} 
al hablar del concepto de legado y podemos apreciar en la sección «Puentes entre el pasado y el presente» de Kapelusz (en torno a Malvinas, la música, la política) ${ }^{163}$ y en alguna actividad, en la que se pregunta por «las consecuencias de aquellas dictaduras para la región y [las que] persisten en la actualidad». ${ }^{164}$ Aquí también se discuten las «Interpretaciones sobre la última dictadura militar», la teoría de los dos demonios y diversos materiales. ${ }^{165}$ Y sobre todo se abordan las categorías que se manejaron entonces y manejamos ahora, como «la democracia», sobre cuyos variables significados se pide investigar, tanto en lo que toca a gente común ${ }^{166}$ como a Alfonsín en sus discursos. ${ }^{167}$

Hay aquí igualmente un recelo frente a la historia oral que exige una "cuidadosa revisión crítica», dados los presuntos engaños de la memoria; ${ }^{168}$ esta misma suspicacia aparece cuando se señala, a propósito del debate público, que «muchas veces se entrecruzan cuestiones académicas y cívicas». ${ }^{169}$ Por lo demás, se rechazan las naturalizaciones de ciertos términos, ya que se dice que Viola «sucedió» a Videla, se habla del «relevo» de Viola por Galtieri y se señala que Galtieri fue «reemplazado» por Bignone. ${ }^{170}$ Sin embargo, también hay referencias a la sucesión de Videla por Viola «en la presidencia de la nación» y al nombramiento de Bignone como «nuevo presidente»; incluso se menciona «la gestión de Bignone». ${ }^{171} \mathrm{Y}$ al mismo tiempo hay una manifiesta proximidad con respecto al lenguaje de los organismos de derechos humanos, de manera similar a la que hemos apreciado en el relato previo; ${ }^{172}$ prueba de ello podría ser la correspondencia entre las designación de la sección «Puentes entre el pasado y el presente» de Kapelusz y el nombre de la revista

\footnotetext{
163 De Amézola et al., Historia argentina, 223, 272.

164 Andújar et al., Historia argentina, 280.

165 Andújar et al., Historia, 188 Y 189 (actividad nº 9); Andújar et al., Historia argentina, 325.

166 De Amézola et al., Historia argentina, 237, actividad 6.

167 Andújar et al., Historia argentina, 281.

168 Andújar et al., Historia argentina, 273.

169 Andújar et al., Historia, 188.

170 Andújar et al., Historia, 185; Andújar et al., Historia argentina, 271 y 276.

171 Andújar et al., Historia, 185 y 187.

172 Andújar et al., Historia, 219 y 165.
} 
de la Comisión Provincial por la Memoria de Buenos Aires, editada desde 2000, Puentes.

\section{DISCUSIÓN}

El análisis realizado sobre los contenidos relativos al pasado reciente manifiesta primeramente una síntesis del conocimiento histórico apto para transmitirse a los jóvenes en las escuelas y, por tanto, el material concreto del que éstos disponen para conformar lo que saben. ${ }^{173}$

Sin embargo, esa aptitud para la transmisión no es una cualidad natural, sino que se construye en relación con distintos factores, como el económico (en términos de rentabilidad mercantil) y el político. Y es este último, particularmente, el que nos lleva a entender los textos también como síntesis de una «versión oficial» de la historia y como herramientas destacadas en la reproducción de «los valores predominantes de cualquier sociedad ${ }^{174}$ y de modelos de socialización y actuación que buscan cohesionar culturalmente a la nación. ${ }^{175}$ En este marco debe entenderse la existencia de una narración con iconos y cánones, y con el procesamiento de algunos responsables como nodo, así como la presentación de la transición como el momento revelador de la verdad a la sociedad, concebida monolíticamente. A esto se añaden ciertas convergencias acerca del carácter autoevidente y teleológico del proceso. Estos elementos constatan una versión socialmente aceptada (y aceptable), un consenso para la refundación nacional que se mantiene en la actualidad como forma de identificar y cohesionar a la población.

Aun así, en este estudio hemos encontrado una tremenda variedad, cosa que implica que en la Argentina de principios del siglo XXI no existe una (o la) versión oficial. Más bien hay distintas maneras en las que se recontextualizan las normas oficiales, el saber académico o disciplinar y múltiples valores, costumbres y relaciones sociales. ${ }^{176}$ El reto en el

\footnotetext{
173 Carretero, Jacott y López-Manjón, «La enseñanza», 154.

174 Mario Carretero y James F. Voss, «Prefacio», en Aprender y pensar la historia, comps. Mario Carretero y James F. Voss (Buenos Aires y Madrid: Amorrortu, 2004), 19.

175 Carbone, Libros escolares, 29-30.

176 Bernstein, Pedagogía.
} 
estudio de manuales es precisamente dar cuenta de esta variedad y explicarla.

Por ello, dejando a un lado que los textos analizados muestran cómo se aplica el marco normativo oficial de 1993 y 2006 (cosa que requeriría un trabajo específico), podemos apreciar en tercer lugar una serie de aspectos relativos al campo disciplinar. El núcleo de los relatos sobre la transición es la «crisis» (política, económica, social... de la dictadura, o del país en un contexto temporal más amplio), de modo que pueden entenderse como parte de un marco de significaciones argentino, que sirve tradicionalmente para dar sentido a la realidad sociohistórica del país. ${ }^{177}$ Además, la vinculación de «democracia» y «dictadura» (o «autoritarismo»), en términos tanto de sucesión temporal (etapas) como de oposición ontológica (regímenes esencializados), remite a la llamada «pareja conceptual contraria asimétrica» ${ }^{178} \mathrm{O}$ «dualismo antinómico o antagónico», ${ }^{179}$ que integra ese marco de significaciones como parte de una «teodicea secular» que se va planteando en contextos específicos para releer históricamente cada momento. ${ }^{180}$ Como parte del discurso compartido, la transición trasciende lo institucional y hunde sus raíces en la «cultura» y los «valores» (democráticos y autoritarios), por ejemplo en los discursos de Alfonsín, como parte del «sentido común» del que nos hablaron José Nun y Guillermo O’Donnell. ${ }^{181}$

Pero, más allá de estas convergencias, hemos constatado importantes divergencias, al rastrear los vínculos que se proponen entre los polos del binomio. Así, en el relato de la ruptura se esencializan los términos de esa pareja (como regímenes ajenos uno respecto al otro) y en el de la continuidad se historizan (como etapas de una secuencia marcada por los procesos); a ellos se suma uno intermedio que defiende también una oposición de esencias, pero acepta su vinculación histórica mediante el

\footnotetext{
177 Sergio Visacovsky y Rosana Guber, «¿Crisis o transición? Caracterizaciones intelectuales. Del dualismo argentino en la apertura democrática», Anuario de Estudios Americanos 62, no. 1 (2005): 52 y $62-64$.

178 Cecilia Lesgart, Usos de la transición a la democracia. Ensayo, ciencia y política en la década del '80 (Rosario: Homo Sapiens, 2003), 67.

179 Visacovsky y Guber, «¿Crisis o transición?».

180 Visacovsky y Guber, «¿Crisis o transición?», 65.

181 Lesgart, Usos, 58 y 74-77.
} 
concepto de legado, que no articula orgánicamente los polos. De aquí se deriva una caracterización histórica distinta: una tendencia inmanente hacia un destino compartido (guiado por la racionalidad instrumental), por más que a veces sea circular, que naturaliza muchos de los acontecimientos y procesos, y la intervención de múltiples factores concretos (como las luchas de poder), que los determinan múltiplemente. Una serie de presupuestos epistemológicos apuntalan estas características (o las fundamentan), pues en el caso del positivismo a secas se promueve la escisión de etapas y regímenes (y la separación neta entre pasado y presente) y en el del positivismo crítico se rechaza, y se incorporan de forma natural categorías centrales en aquél mientras se discute su especificidad en éste.

Con todo, en los relatos sigue faltando una relación orgánica (desde el punto de vista histórico y no tanto filosófico) entre los términos del dualismo, como veíamos incluso con el relato de la continuidad. Aquí no permean, o no se articulan, cuestiones básicas: durante la dictadura de 1976-1983 los propios jerarcas aludían constante y preferentemente a «la democracia» (la «auténtica» democracia); 182 se produjeron múltiples negociaciones (cuando no las famosas «cenas»), en torno a la "convergencia», entre los grupos y personalidades más identificados con el Proceso y otros aparentemente ajenos a él (Ernesto Sábato, Fernando de la Rúa, Ricardo Balbín, el propio Alfonsín, Borges...), ${ }^{183}$ y las propias juntas se refirieron a la idea de «transición» desde al menos fines de 1977, ${ }^{184}$ por no hablar de la duradera "política económica como política de poder» de Martínez de Hoz y los suyos. ${ }^{185}$ Además, la propia «raigambre histórica de los términos» que manejamos exigiría ponerlos en relación con procesos concretos, como la «reorganización de las relaciones sociales», 186 que

182 Marcos Novaro y Vicente Palermo, La dictadura militar 1976-1983 (Buenos Aires: Paidós, 2003), 20 y 45; Mensajes Presidenciales. Proceso de Reorganización Nacional. 24 de marzo de 1976, Tomo 1 (Buenos Aires: Secretaría de Información Pública, 1976), 26-27.

183 Novaro y Palermo, La dictadura, 164, 181-183, n. 7 y 234-235; César Tcach, «Radicalismo y dictadura (1976-1983)», en A veinte años del golpe. Con memoria democrática, comps. Hugo Quiroga y César Tcach (Rosario: Homo Sapiens, 1996), 27-50.

184 Novaro y Palermo, La dictadura, 173 y 244.

185 Jorge Schvarzer, «La política económica como política de poder», en A veinte años del golpe. Con memoria democrática, comps. Hugo Quiroga y César Tcach (Rosario: Homo Sapiens, 1996), 107-122.

186 Daniel Feierstein, El genocidio como práctica social: entre el nazismo y la experiencia argentina (Buenos Aires: FCE, 2011), 104-110. 
relegan algunos («revolución», «justicia social») e imponen otros («democracia», «derechos humanos»). ${ }^{187}$ El desinterés hacia estas cuestiones historiográficas contribuye a los consensos aludidos sobre el saber aceptado y aceptable en la Argentina actual.

En cuarto lugar, los relatos analizados van más allá de lo disciplinar y hunden sus raíces en las disputas por difundir y asentar determinadas interpretaciones en el campo social. La intensidad de la pugna se aprecia, por ejemplo, en los usos de los términos más extendidos entre muchos organismos de derechos humanos, en el caso de los relatos de la continuidad y la transición propiamente, y en su rechazo soterrado (junto con el empleo de otros que hemos calificado de naturalizadores), en el de la ruptura, así como en los reparos de éste a la hora de abordar con «objetividad» este pasado «muy reciente» (y sus suspicacias respecto de los que lo hacen) y en la ardiente defensa de un «relato histórico diferente» y el compromiso para construir "puentes entre el pasado y el presente» por parte de los otros dos.

Los vínculos con las memorias sociales se aprecian en dos sentidos. Por un lado, sin salirnos del campo de los manuales, hay correspondencia entre los relatos de la continuidad y la transición propiamente con los textos de carácter denunciante de Born. ${ }^{188} \mathrm{~A}$ su vez, y validando la distinción entre ambos, el primero correspondería a los críticos integrales, ${ }^{189}$ dadas las permanencias por la profunda labor de transformación del país y la suavización del antagonismo dictadura-democracia. Y el segundo se aproxima al crítico institucional, pues el interés lo sitúa en la ruptura del orden constitucional con el golpe de 1976 y en las consecuencias («legados») en los años posteriores. El de la ruptura se vincula también con el crítico institucional, aunque omite estas peculiares continuidades del de la transición propiamente.

Por otro lado, hay convergencias entre los textos y las representaciones de los estudiantes sobre el pasado reciente. La correlación primordial se establece entre la llamada memoria de los gobiernos constitucionales, ${ }^{190}$

\footnotetext{
187 Jelin, La lucha, cap. 2.

188 Born, «Las representaciones», 90-91.

189 Born, «Las representaciones», 108-115.

190 Ana Pereyra, «La relación de los adolescentes con la historia reciente de Argentina. Un estudio exploratorio de la conciencia histórica entre estudiantes de escuelas medias públicas de la ciudad de
} 
o memoria del Nunca Más, ${ }^{191}$ o memoria victimizante, ${ }^{192}$ y el relato de la transición propiamente, dado que esas memorias tienden a recalcar la ruptura del orden constitucional en 1976. Aun así, este relato vimos que insistía en la indeterminación del proceso y en la agencia de los participantes, y no reproduce la teoría de los dos demonios (la otra característica importante de la memoria constitucionalista); por ello, y por la presencia de un lenguaje próximo a muchos organismos de derechos humanos, también se puede ligar a la memoria de éstos (según la definió Pereyra) o incluso a la memoria hipervictimizante (sensu Kriger). El relato de la continuidad es el que más se aproxima a la memoria de los organismos de derechos humanos, tanto por los términos empleados, como por apelar a la trascendental obra de transformación. El de la ruptura contiene también elementos de la memoria de los gobiernos constitucionales, pero converge con la memoria militar (definida por todas las autoras citadas) en cuanto al uso naturalizador de ciertas categorías («subversión») y signos gráficos (comillas), y a la justificación del accionar cívico-militar amparada en la racionalidad instrumental. El planteamiento positivista generalizado, que apuesta por un acercamiento a la verdad a través de narraciones lo más asépticas (u objetivas) posibles, concuerda con el modelo de la historia. ${ }^{193}$

La vinculación con el campo social suscita una última reflexión. Aunque es esencial abordar cómo estudiantes y docentes leen, traducen, se apropian de las narraciones, ${ }^{194}$ resulta claro que los «marcos de significaciones» no son sólo modelos de (la realidad) sino también modelos para intervenir en ella. ${ }^{195}$ Específicamente, lo que se enseña sobre la transición supone un conjunto de «categorías evaluativo-descriptivas»

\footnotetext{
Buenos Aires» (Tesis doctoral, Facultad Latinoamericana de Ciencias Sociales, 2007), cap. 8, 214215.

191 Florencia Levin et al., «El pasado reciente en la escuela. Análisis y reflexiones a propósito de las representaciones estudiantiles de la última dictadura militar argentina», Iber 55 (2003): 98-100.

${ }_{192}$ Miriam Kriger, «La enseñanza de la historia reciente como herramienta clave de la educación política», Persona y Sociedad XXV, no. 3 (2011): 41-42.

${ }^{193}$ Florencia Levin et al., «El pasado reciente en la escuela».

194 James V. Wertsch, La mente en acción (Buenos Aires: Aique); Carbone, Libros escolares, 35-44; Ossenbach, «Prólogo», 10.

${ }_{195}$ Visacovsky y Guber, «¿Crisis o transición?», 56.
} 
que incluyen aprendizajes sobre «cómo debe llevarse a cabo [el cambio político]». ${ }^{196}$

El relato de la ruptura tenderá a escamotear los procesos históricos de negociación y pactismo entre viejas y nuevas élites, así como la perpetuación de determinadas relaciones y posiciones de privilegio y dominación, y también la impunidad; igualmente, dado el planteamiento teleológico, dificultará la discusión del presente y sus raíces históricas, y del carácter construido (y necesariamente revisable) del sistema constitucional republicano. El de la continuidad podrá favorecer la consideración de esas maniobras y esos vínculos, aunque también promoverá, directa o indirectamente, el presentismo y, por tanto, los anacronismos; con ello, entre otras cosas, se obviaría la especificidad histórica de determinados fenómenos y procesos (como la violencia política en democracia). El de la transición propiamente, lejos de lograr un equilibrio entre ambos relatos, potenciaría los efectos negativos de uno y otro. Aun así, en todos ellos, dadas las convergencias citadas, predomina la idea de la transición como un momento de refundación en un sentido liberal republicano, como una oportunidad para garantizar un destino compartido, relegando cuestiones que se sacaron del debate y las agendas a fuerza de violencia política masiva.

Al mismo tiempo, la transición se presta a un ejercicio crítico de gran potencial en el marco de la pedagogía de la memoria, pues trata un tema, un momento en el que nada (o muy poco) estaba realmente fijado, uno de esos momentos de contacto entre realidades con posibilidades de ser distintas, un espacio y tiempo liminales de lo efectivo y lo posible. Igual que la piel no es sólo la capa superficial del cuerpo, sino el punto de encuentro entre el organismo y el mundo, y en ella se debaten cuestiones esenciales de la salud (de dentro y de fuera), así también la transición es la juntura entre lo que fue/es y lo que pudo/puede ser. Pensar en ello permite no sólo entender las formas en que se han producido los acontecimientos, sino también abrir puertas a lo posible.

196 Lesgart, Usos, 71. 


\section{Nota sobre el autor}

JoRge Rolland investiga sobre enseñanza de la historia reciente en el Instituto de Investigaciones Sociales de América Latina (FLACSO-CONICET). Ha participado en proyectos sobre historia reciente, como el del destacamento penal franquista de Bustarviejo (Madrid), y cuenta con diversas publicaciones sobre arqueología teórica, arqueología del conflicto y enseñanza de la historia reciente.

\section{REFERENCIAS}

Acosta, Juan. «La historia reciente en la escuela. Análisis de los manuales del nivel medio luego de la sanción de la Ley Nacional de Educación en 2006». Clío \& Asociados 20-21 (2015): 149-161.

Alonso, Fabiana. «La dictadura militar argentina (1976-1983) en los textos escolares de Ciencias Sociales e Historia para el Tercer Ciclo de la Educación General Básica». De Signos y Sentidos 2 (2004): 9-29.

Alonso, Fabiana. «Capítulo VII. La dictadura militar argentina (1976-1983) en los textos escolares de Ciencias Sociales e Historia para el tercer ciclo de la Educación General Básica». En Dictadura y educación. Volumen 3. Los textos escolares en la Historia argentina reciente, editado por Carolina Kaufmann, 273-294. Buenos Aires: Miño y Dávila, 2006.

Alonso, María Ernestina y Enrique C. Vázquez. Historia: la Argentina contemporánea: 1852-1999. Buenos Aires: Aique, 2006. (1ª ed., $4^{\mathrm{a}}$ reimp.).

Andújar, Andrea N. et al. Historia argentina en el contexto latinoamericano y mundial (1850 hasta nuestros días). Buenos Aires: Santillana, 2012.

Andújar, Andrea N. et al. Historia. $5^{\circ}$ año. Buenos Aires: Santillana, 2017.

Bernstein, Basil. Pedagogía, control simbólico e identidad. Madrid: Morata, 1998.

Born, Diego Ariel. «Las representaciones de la última dictadura militar. Los textos escolares de Historia en el nivel Secundario de la Ciudad de Buenos Aires, 1976-2009». Tesis de Maestría, Facultad Latinoamericana de Ciencias Sociales, 2010.

Carbone, Graciela. Libros escolares. Una introducción a su análisis y evaluación. México: Fondo de Cultura Económica, 2003.

Carretero, Mario y James F. Voss. «Prefacio». En Aprender y pensar la historia, compilado por Mario Carretero y James F. Voss, 13-22. Buenos Aires y Madrid: Amorrortu, 2004.

Carretero, Mario, Jacott, Liliana y Asunción López-Manjón. «La enseñanza de la historia mediante los libros de texto: ¿se les enseña la misma historia a los alumnos mexicanos que a los españoles». En Aprender y pensar la historia, 
compilado por Mario Carretero y James F. Voss, 153-172. Buenos Aires y Madrid: Amorrortu, 2004.

Carretero, Mario, Alberto Rosa y María Fernanda González. «Introducción. Enseñar historia en tiempos de memoria». En Enseñanza de la historia y memoria colectiva, compilado por Mario Carretero, Alberto Rosa y María Fernanda González, 13-38. Buenos Aires: Paidós, 2006.

Castorina, José Antonio. «Un encuentro de disciplinas: la historia de las mentalidades y la psicología de las representaciones sociales». En Enseñanza de la historia y memoria colectiva, compilado por Mario Carretero, Alberto Rosa y María Fernanda González, 73-90. Buenos Aires: Paidós, 2006.

De Amézola, Gonzalo et al. Historia argentina y latinoamericana II en el contexto de las transformaciones mundiales (desde 1930 hasta el presente). Buenos Aires: Kapelusz/Norma, 2004.

De Amézola, Gonzalo, Carlos A. Dicroce, y María Cristina Garriga. «La última dictadura militar argentina en los manuales de Educación General Básica». En Textos escolares, dictaduras y después. Miradas desde Argentina, Alemania, Brasil, España e Italia, editado por Carolina Kaufmann, 103-134. Buenos Aires: Prometeo, 2012.

De Amézola, Gonzalo. «Capítulo VI. Cambiar la Historia. Manuales escolares, currículum y enseñanza de la historia reciente desde la transformación educativa». En Dictadura y educación. Volumen 3. Los textos escolares en la Historia argentina reciente, editado por Carolina Kaufmann, 227-271. Buenos Aires: Miño y Dávila, 2006.

Eggers-Brass, Teresa. Historia VI: historia reciente en la Argentina. Ituzaingó: Maipue, 2016.

Feierstein, Daniel. El genocidio como práctica social: entre el nazismo y la experiencia argentina. Buenos Aires: FCE, 2011.

Henne, Kathrin (ed.). Textbooks between tradition and innovation. A journey through the history of the Georg Eckert Institute. Brunswick: Georg Eckert Institute y Leibniz Institute for International Textbook Research, 2016.

Jelin, Elisabeth. La lucha por el pasado. Cómo construimos la memoria social. Buenos Aires: Siglo XXI, 2017.

Kaufmann, Carolina (ed.). Dictadura y educación. Volumen 3. Los textos escolares en la Historia argentina reciente. Buenos Aires: Miño y Dávila, 2006.

Kriger, Miriam. «La enseñanza de la historia reciente como herramienta clave de la educación política. Narrativas escolares y memorias sociales del pasado dictatorial argentino en las representaciones de jóvenes estudiantes de la Ciudad de Buenos Aires y conurbano (2010-2011)». Persona y Sociedad XXV, no. 3 (2011): 29-52.

Legarralde, Martín. «Estudios sobre la transmisión escolar de las memorias de la última dictadura militar». Archivos de Ciencias de la Educación 6, no. 6 (2012): http://www.memoria.fahce.unlp.edu.ar/art_revistas/pr.5933/pr.5933.pdf. 
Lesgart, Cecilia. Usos de la transición a la democracia. Ensayo, ciencia y política en la década del '80. Rosario: Homo Sapiens, 2003.

Levin, Florencia et al. «El pasado reciente en la escuela. Análisis y reflexiones a propósito de las representaciones estudiantiles de la última dictadura militar argentina». Iber 55 (2003): 93-102.

Losada, Leandro et al. Historia 2. Historia argentina y latinoamericana (19002005). Buenos Aires: Tinta Fresca, 2007.

Mahamud, Kira y Anna Ascenzi (eds.). «Textbooks in Periods of Political Transition after the Second World War. Special Issue». Journal of Educational Media, Memory and Society 9, no. 1 (2017): 1-117.

Mensajes Presidenciales. Proceso de Reorganización Nacional. 24 de marzo de 1976. Tomo 1. Buenos Aires: Secretaría de Información Pública, diciembre de 1976.

Novaro, Marcos y Vicente Palermo. La dictadura militar 1976-1983. Buenos Aires: Paidós, 2003.

Ossenbach, Gabriela. «Prólogo». En Dictadura y educación. Volumen 3. Los textos escolares en la Historia argentina reciente, editado por Carolina Kaufmann, 7-12. Buenos Aires: Miño y Dávila, 2006.

Pereyra, Ana. «La relación de los adolescentes con la historia reciente de Argentina. Un estudio exploratorio de la conciencia histórica entre estudiantes de escuelas medias públicas de la ciudad de Buenos Aires». PhD diss., Facultad Latinoamericana de Ciencias Sociales, 2007

Piccolini, Patricia et al. Historia. El mundo contemporáneo. Buenos Aires: Estrada, 2008.

Rins, Cristina y María Felisa Winter. La Argentina. Una historia para pensar 1776-1996. Buenos Aires: Kapelusz, 1999.

Romero, Luis Alberto (coord.). La Argentina en la escuela. La idea de nación en los textos escolares. Buenos Aires: Siglo XXI, 2004.

Schvarzer, Jorge. «La política económica como política de poder». En A veinte años del golpe. Con memoria democrática, compilado por Hugo Quiroga y César Tcach, 107-122. Rosario: Homo Sapiens, 1996.

Tcach, César (1996): «Radicalismo y dictadura (1976-1983)». En A veinte años del golpe. Con memoria democrática, compilado por Hugo Quiroga y César Tcach, 27-50. Rosario: Homo Sapiens, 1996.

Visacovsky, Sergio y Rosana Guber. «¿Crisis o transición? Caracterizaciones intelectuales. Del dualismo argentino en la apertura democrática». Anuario de Estudios Americanos 62, no. 1 (2005): 55-85.

Wertsch, James V. La mente en acción. Buenos Aires: Aique, 1998.

Zysman, Nadya. De la «subversión marxista» al «terrorismo de Estado». Representaciones de la última dictadura militar en las narrativas históricas de la escuela media argentina (1983-2009). Córdoba: Editorial Universitaria Villa María, 2015. 